\title{
Medios de comunicación y marcas turísticas: la labor de las oficinas extranjeras de turismo en España
}

\author{
Beatriz GonZÁLEZ SANTOS \\ Universitat Pompeu Fabra \\ mabegon@gmail.com \\ José FERnÁndez CAVIA \\ Universitat Pompeu Fabra \\ jose.fernandez@upf.edu \\ Daniel TENA PARERA \\ Universitat Autònoma de Barcelona \\ daniel.tena@uab.cat
}

Recibido 28 de mayo de 2013

Aceptado: 21 de octubre de 2013

\begin{abstract}
Resumen
Este artículo examina las acciones que realizan las oficinas nacionales de turismo en el extranjero, para lograr uno de sus objetivos de comunicación principales: fomentar el interés en el destino turístico a través de una presencia positiva en los medios. Con este fin, fueron conducidas entrevistas cualitativas a directivos y responsables de comunicación de cinco oficinas de destinos turísticos establecidas en España. Los resultados obtenidos apoyan otros estudios que sugieren el papel fundamental de la publicity en la comunicación de las marcas de destinos turísticos. Asimismo, evidencian que la práctica de estas oficinas transcurre en una adaptación constante a su entorno sociopolítico, económico y tecnológico, y se ve impactada por el desarrollo de nuevos medios basados en Internet.
\end{abstract}

Palabras clave: Destination branding, medios de comunicación, periodismo de turismo y de viajes, publicity.

\section{Media and destination brands: the work of the foreign offices of tourism in Spain}

\begin{abstract}
This paper examines the activities of the national tourism offices abroad, oriented to achieve one of its main communication objectives: to increase the public interest on the destination through a positive presence in the media. Qualitative interviews were conducted with managers and public relations managers of five tourist destinations offices established in Spain. The results support other studies that suggest that publicity has an important role in the communication mix of such organizations. Also, it shows that the practice of these offices is continuously adapting to their sociopolitical, economic and technological environment and is affected by the development of new media based on Internet.
\end{abstract}

Keywords: Media, destination branding, tourism and travel journalism, publicity

1 Este trabajo ha sido financiado parcialmente por el proyecto "Comunicación online de los destinos turísticos. Desarrollo de un instrumento de evaluación integrada de la eficacia: sitios web, dispositivos móviles y web social (CODETUR)" (CSO 2011-22691), del Ministerio de Economía y Competitividad (España). Puede encontrarse más información en: www.marcasturisticas.org 


\section{Referencia normalizada}

GONZÁLEZ SANTOS, Beatriz; FERNÁNDEZ CAVIA, José; y TENA PARERA, Daniel (2014): “Medios de comunicación y marcas turísticas: la labor de las oficinas extranjeras de turismo en España”. Estudios sobre el Mensaje Periodístico. Vol. 20, Núm. 1 (enero-junio), págs.: 413-429. Madrid, Servicio de Publicaciones de la Universidad Complutense.

Sumario: 1. Introducción; 1.1. Comunicación turística y marca país; 1.2. Fuentes de información en la comunicación turística; 1.3. Las ONTE: entre el periodismo y las relaciones públicas; 1.4. Herramientas de publicity para las ONTE. 2. Objetivos y metodología. 3. Resultados; 3.1. Los públicos a los que se dirigen las acciones de comunicación de las ONTE; 3.2. Herramientas, acciones y medios de promoción; 3.3. Resultados de las acciones y evaluación; 3.4. Tendencias y retos. 4. Conclusiones. 5. Agradecimientos. 6. Referencias bibliográficas.

\section{Introducción}

En el ámbito de lo que se considera periodismo especializado, podemos englobar el periodismo de turismo y de viajes, como un subsector en auge en cuanto a espacio en los medios, y de futuro creciente si atendemos a la popularización de la actividad turística que ha venido de la mano de la globalización, la generalización del uso de las nuevas tecnologías y los vuelos low cost.

En este ámbito, las labores de los gabinetes y oficinas de comunicación de los destinos turísticos ejercen una influencia notable en la actividad de los periodistas. A través de acciones generales como notas de prensa, o de acciones más especializadas como press trips o blog trips, las Oficinas Nacionales de Turismo en el Extranjero (ONTE) tratan de difundir las características, valores y ventajas de sus países de origen y transmitir a través de los medios una imagen positiva de sus destinos a los turistas potenciales.

Este tipo de prácticas han generado entre profesionales e investigadores críticas más o menos explícitas, más o menos enérgicas: Cáceres, por ejemplo, opina que "con la proliferación de los gabinetes de prensa en el periodismo actual, frecuentemente es la fuente la que hace la noticia" (2011: 306). Es lo que otros autores denominan "periodismo de fuente" (Losada y Esteve, 2003). El periodismo de fuente desempeña, sin embargo, un papel fundamental en el sector turístico, ya que sirve para trasladar a la opinión pública una visión positiva del país y, al mismo tiempo, para promocionarlo como destino de viajes.

No obstante, la actividad de las ONTE se mueve en fronteras difusas, combinando estrategias y acciones diversas, que pueden vincularse a menudo con el periodismo de fuente, pero que, también con frecuencia, se sitúan en el terreno de las relaciones públicas, la publicidad o la publicity².

\subsection{Comunicación turística, branding y marca país}

$\mathrm{Al}$ analizar la comunicación turística, y específicamente en el caso de la comunicación de destinos, uno de los términos que más se ha popularizado desde finales del siglo

2 Entenderemos aquí la publicity, en su acepción anglosajona, como el conjunto de actividades realizadas por una empresa, organización o institución pública con el fin de generar noticias positivas en los medios de comunicación, sin que exista remuneración a cambio. 
XX es el de branding. En su acepción inicial, el concepto de branding se aplicó en la disciplina del marketing, y consiste en dotar del poder de una marca a los productos y los servicios que se quiere comercializar (Kotler y Keller, 2006:287). Esta marca debe ayudar a los consumidores a crear estructuras mentales y a organizar sus conocimientos sobre productos y servicios, de manera que sirva para crear diferencias relevantes que guíen sus decisiones.

Si se aplican estos procesos a los destinos turísticos, podemos hablar de destination branding, una práctica que, según Blain, Levy y Ritchie (2005: 337), consiste en las siguientes acciones, que, en su conjunto, deben servir para crear una imagen del destino que influya de manera positiva en la selección por parte del posible turista:

a) crear un nombre de marca, con su logotipo y símbolo correspondiente, que identifique y diferencie un destino;

b) transmitir la promesa de una experiencia de viaje memorable, asociada, de manera única a este destino;

c) consolidar y reforzar la recolección de recuerdos agradables de la experiencia de viaje; $y$

d) reducir los costes de búsqueda y el riesgo percibido de los consumidores.

Los destinos a los que se aplican estas técnicas pueden ser de diversa índole. Si atendemos al tamaño o a la clasificación administrativa, puede tratarse de ciudades, regiones o naciones. Evidentemente, dependiendo de la tipología del destino, la complejidad e implicaciones de su gestión son muy diferentes.

Para el caso de las naciones, en que las labores del branding convergen en muchos aspectos con las de la diplomacia pública (Szondi, 2008), se ha acuñado un término específico, que es el de nation branding, utilizado por primera vez por el investigador Simon Anholt (1998).

Este mismo autor ha modificado recientemente su punto de vista y prefiere utilizar ahora el término de "identidad competitiva", ya que argumenta que la imagen y reputación de los estados no están vinculadas únicamente a su promoción turística, sino que están más relacionadas con su identidad nacional, su política y su competitividad económica que con los procesos tradicionales de creación y gestión de marcas (Anholt, 2007: xi).

No obstante, el concepto de nation branding sigue utilizándose, como podemos comprobar, por ejemplo, en la obra de Dinnie (2008), quien define la marca-país como "la combinación única y multidimensional de elementos que proporcionan a la nación una diferenciación y relevancia, culturalmente fundamentadas, para todas las audiencias a las que se dirige" (2008: 15). O en un artículo de Kaneva (2011), que demanda en su texto una mayor atención por parte de los investigadores académicos en comunicación hacia este fenómeno emergente.

En cualquier caso, cada vez son más los países que le dedican a la promoción turística un elevado volumen de recursos, ya sea a través de campañas publicitarias globales, ya sea a través del establecimiento en los mercados emisores (es decir, en los países de origen de sus turistas) de una red de oficinas de comunicación y promoción que llevan a cabo estrategias específicamente adaptadas a sus públicos respectivos. 


\subsection{Fuentes de información en la comunicación turística}

Los turistas potenciales, a la hora de buscar activamente o recibir de manera pasiva información acerca de destinos posibles, interactúan con fuentes diversas, que han tratado de ser clasificadas por algunos autores. Castelltort y Mäder (2010: 725), por ejemplo, recogen la clasificación de Gartner, que a partir de la diferenciación tradicional entre imagen orgánica (aquella en cuya formación no intervienen labores profesionales de promoción) e imagen inducida (aquella provocada por las acciones de promoción del destino), propone la siguiente tipología de agentes:

Tabla 1. Agentes que intervienen en la formación de la imagen de destinos turísticos.

Fuente: Castelltort y Mäder, 2010

\begin{tabular}{|l|l|}
\hline \multicolumn{1}{|c|}{ Agente } & \multicolumn{1}{c|}{ Descripción } \\
\hline Directo inducido I & Publicidad tradicional. \\
\hline Directo inducido II & $\begin{array}{l}\text { Información recibida o solicitada a través de operadores turísticos y } \\
\text { otras organizaciones con intereses en el proceso de decisión del } \\
\text { viaje, pero que no están vinculadas a un destino en concreto. }\end{array}$ \\
\hline Indirecto inducido I & $\begin{array}{l}\text { A través de una celebridad o la recomendación de un consumidor } \\
\text { satisfecho. }\end{array}$ \\
\hline Indirecto inducido II & $\begin{array}{l}\text { Resultado de viajes de familiarización para periodistas a través de } \\
\text { publicaciones imparciales, sin interés específico en incrementar los } \\
\text { viajes al destino. }\end{array}$ \\
\hline Autónomo & $\begin{array}{l}\text { Reportajes independientes, documentales, películas y noticias en los } \\
\text { medios de comunicación. }\end{array}$ \\
\hline No solicitado orgánico & $\begin{array}{l}\text { Información no solicitada recibida a través de personas que han } \\
\text { visitado el destino o que creen que lo conocen. }\end{array}$ \\
\hline Solicitado orgánico & $\begin{array}{l}\text { Información solicitada a los amigos o resultado de la búsqueda } \\
\text { activa. }\end{array}$ \\
\hline Orgánico & Visita al destino. \\
\hline
\end{tabular}

En todas estas categorías, salvo en las tres últimas, la participación o intermediación de las ONTE puede resultar decisiva. A efectos del presente trabajo, son las categorías "Indirecto inducido I", "Indirecto inducido II" y "Autónomo" las que más nos interesarían, y las que centrarán la investigación, por estar directamente vinculadas con la publicity.

Precisamente, según Loda et al. (2007), la publicidad y la publicity son las dos fuentes principales de información para los turistas potenciales, y las dos herramientas de comunicación más utilizadas por los responsables de promoción de los destinos. Según su estudio, las noticias y los contenidos no pagados recogidos por los medios son capaces, sin embargo, de transmitir mayor credibilidad, fuerza del mensaje e intención de compra y son, por estos motivos, más eficaces que la propia publicidad.

\subsection{Las ONTE: entre el periodismo y las relaciones públicas}

Toda marca de destino turístico está gestionada por un organismo público o semipúblico encargado de la gestión estratégica y operativa. Pero esta gestión acostumbra a entrañar una gran complejidad, debido a que un destino -a diferencia de un producto de consumo- no es un objeto unitario, sino vasto y complejo, sobre todo en el caso de las naciones. 
En este contexto se sitúa la labor de las Organizaciones Nacionales de Turismo (ONT), entes encargados de la promoción turística del país correspondiente y que, a su vez, cuentan con diversas Oficinas Nacionales de Turismo en el Extranjero (ONTE) para encargarse de las labores de comunicación en un país o mercado emisor específico.

Entre las funciones de las ONT se encuentra la conceptualización de las campañas de marketing, el diseño de estrategias de promoción, y la implementación del programa. También son responsables del diseño de textos publicitarios, folletos, anuncios para los medios, y otras publicaciones para apoyar las campañas; sin embargo, a veces la producción de estas actividades es subcontratada a una empresa privada. La mayoría de las ONT usualmente se encargan de operar la red de oficinas ubicadas en el exterior (ONTE), cuya función es promover el destino en los mercados extranjeros. Estas oficinas se valen de la combinación de varias herramientas para comunicar de forma persuasiva el valor de la marca de destino y crear una relación positiva con el público, las principales son: la publicidad, el marketing directo, las promociones de venta, la venta personal, las relaciones públicas y la publicity.

Canel (2007:252), al hablar de la comunicación que se realiza desde las instituciones públicas, recuerda que en las relaciones informativas entre medios e instituciones existen intereses comunes, ya que los primeros necesitan información de actualidad relevante para sus lectores, mientras que las segundas desean ver representados sus intereses de manera positiva ante los ciudadanos, de manera que estos desarrollen una actitud positiva ante las decisiones tomadas o hacia las propias instituciones.

De manera similar, las organizaciones promotoras del turismo utilizan esa relación con los periodistas para transmitir una imagen positiva de sus destinos, de manera que puedan atraer visitantes potenciales. La misma autora cita en su obra una serie de herramientas de la política informativa de las instituciones, que son las siguientes: nota de prensa, videocomunicado, conferencia de prensa, declaraciones, dossier de prensa, entrevistas, filtraciones, exclusivas y encuentros informales con periodistas.

Las ONTE utilizan un buen número de estas herramientas, aunque, aparte de acciones dirigidas a los periodistas de los medios, también llevan a cabo acciones dirigidas a intermediarios turísticos y al consumidor final. Para los destinos turísticos, sin embargo, la relación con los periodistas de viajes resulta fundamental, a pesar de las actitudes enfrentadas que puedan encontrar en estos -desde el escepticismo, por un lado, al interés y el agradecimiento, por otro-(Hanusch, 2011: 74).

\subsection{Herramientas de publicity para las ONTE}

La publicity, en el ámbito de los destinos turísticos, puede definirse como una actividad planificada y diseñada para lograr, a través de la cobertura conseguida en los medios de comunicación, una imagen positiva del destino que influya en las decisiones de los turistas potenciales al elegir sus vacaciones.

Cuenta, como ventajas destacadas frente a la publicidad, con el bajo coste que representa, pues se trata de apariciones por las que no se desembolsa a cambio una retribución, y con una mayor credibilidad que los anuncios publicitarios, por cuanto el receptor de la información confía en la objetividad de la fuente. 
Bajo el concepto de publicity suelen agruparse actividades diversas, aunque las dos principales son la creación de eventos y las relaciones informativas con los medios de comunicación. La importancia de estas acciones en la labor cotidiana de las ONTE es muy elevada, no solo desde el punto de vista del tiempo que ocupan, sino también desde el punto de vista de los recursos que consumen.

Dore y Crouch (2003:142), a partir de una encuesta realizada a 10 organizaciones gestoras de marcas de destinos turísticos nacionales, establecieron que el porcentaje del presupuesto total dedicado a actividades de publicity y relaciones públicas se elevaba al $17 \%$, solo por detrás de lo dedicado a publicidad tradicional (35\%) y a la venta personal a los intermediarios (23\%).

$\mathrm{Y}$, dentro de las actividades que estos autores clasifican como publicity, la que más presupuesto requiere son los viajes de familiarización dirigidos a la prensa, seguidos por las revistas y newsletters, creación de bancos de imágenes y vídeos y las notas de prensa. Precisamente, este primer tipo de acciones, los viajes de familiarización para periodistas son considerados, por los miembros de la muestra, como las de mayor importancia en la promoción del destino, por encima de la publicidad, las ferias o los viajes de familiarización con intermediarios (Dore y Crouch, 2003: 143).

En el contexto de las ONTE, las acciones de relaciones públicas y publicity incluyen, principalmente, las acciones siguientes: la organización de viajes de prensa; el envío de información a los medios a través de notas de prensa o boletines periódicos; el mantenimiento de una biblioteca de recursos audiovisuales, imágenes e información a disposición de los medios; la gestión de la exposición del destino en la televisión y el cine; la organización de eventos; la participación de personalidades como embajadores de turismo; y el mantenimiento de relaciones con los agentes del sector.

\section{Objetivos y metodología}

Presentamos en este artículo un estudio de carácter exploratorio, que tiene como objetivo analizar la planificación y ejecución de las acciones de publicity y relaciones públicas que realizan las ONTE (Oficinas Nacionales de Turismo en el Extranjero) ubicadas en España ${ }^{3}$. Las siguientes preguntas de investigación sirvieron como guía para alcanzar dicho objetivo: 1) ¿Qué estrategias utilizan las ONT para posicionar un destino turístico en España? 2) ¿Qué papel desempeña la publicity dentro de las acciones estratégicas?; 3) ¿Cómo son gestionados los programas de publicity en términos de su ejecución y evaluación?; y 4) ¿Cómo valoran las ONT a la publicity dentro del conjunto de acciones que realizan?

Utilizaremos una metodología cualitativa centrada en la realización de entrevistas en profundidad a los profesionales encargados de la ejecución de estas tareas en las ONTE.

${ }^{3}$ Este artículo se basa en el Trabajo de Investigación Doctoral "La publicity en la promoción de destinos turísticos. Estudio sobre las prácticas de las Oficinas Nacionales de Turismo Extranjeras (ONTE) en el mercado español”, presentado en 2011 por Beatriz González, en la Universidad Autónoma de Barcelona, bajo la dirección del Dr. Daniel Tena Parera. 
Dentro de sus diversas modalidades aplicamos la entrevista semiestructurada, de acuerdo a la definición que aportan Hernández et al. (2008: 597-605): se basa en una guía de asuntos o preguntas abiertas y el entrevistador tiene la libertad de introducir interrogantes adicionales para precisar conceptos u obtener mayor información sobre los temas deseados. La formulación y orden de las preguntas se adecuan a los participantes, y el entrevistador ajusta la comunicación a las normas y lenguaje del interlocutor.

Para la selección de la muestra, se tuvieron en cuenta los criterios siguientes: debía tratarse de responsables de oficina o responsables de comunicación, marketing o relaciones públicas de Oficinas Nacionales de Turismo en el Extranjero situadas en España. Por supuesto, no todos los países tienen oficinas de promoción turística en España, por lo que hubo de elaborarse una lista (con la ayuda de diversos directorios publicados online), que, en abril de 2011, era de 45 oficinas. De ellas, se seleccionó una muestra de las cinco ONTE siguientes: Bélgica: Flandes-Bruselas, Bélgica: Bruselas-Valonia, Suecia, Suiza y República Dominicana.

El guión orientativo de la entrevista constaba de treinta cuestiones organizadas en dos grandes temas: estrategia general de comunicación del destino y acciones concretas de relación con los medios, publicity y relaciones públicas.

Las entrevistas se realizaron en los meses de mayo y junio de 2011, y fueron grabadas en audio, transcritas y procesadas con la ayuda del programa informático MaxQDA (v. 2). Se estableció un sistema de categorías abierto que contempló un total de trece códigos: características del destino, organización y funciones de la ONTE, branding de destinos, estrategia de comunicación, identidad e imagen de marca, herramientas de comunicación, acciones de comunicación, canales propios, canales no propios, públicos estratégicos, resultados de las acciones de comunicación, prescripción/credibilidad y tendencias.

\section{Resultados}

La codificación de las unidades de registro dio como fruto una agrupación en ocho principales núcleos temáticos abordados en las entrevistas, a partir de los cuales se va a organizar la exposición de los resultados. Esos núcleos temáticos, con el detalle de de las frecuencias absolutas y relativas, pueden observarse en la tabla 2:

Tabla 2. Núcleos temáticos y frecuencias correspondientes. Fuente: Elaboración propia.

\begin{tabular}{r|l|r|r}
\hline & \multicolumn{1}{|c|}{ Núcleos temáticos } & \multicolumn{1}{c|}{ Fr } & \multicolumn{1}{c}{$\%$} \\
\hline 1 & Caracterización de las ONTE: estructura y funciones & 79 & 10,52 \\
\hline 2 & Conceptualización del destination branding & 20 & 2,66 \\
\hline 3 & Identidad e imagen de la marca - destino & 61 & 8,12 \\
\hline 4 & Planificación estratégica & 118 & 15,71 \\
\hline 5 & Públicos estratégicos & 103 & 13,72 \\
\hline 6 & Herramientas, acciones y medios de promoción & 257 & 34,22 \\
\hline 7 & Resultados de las acciones y su evaluación & 81 & 10,79 \\
\hline 8 & Tendencias y retos & 32 & 4,26 \\
\hline
\end{tabular}


Los resultados que expondremos en este artículo son aquellos referidos exclusivamente a la relación con los medios por parte de las ONTE y a la planificación y realización de acciones de publicity y relaciones públicas.

\subsection{Los públicos a los que se dirigen las acciones de comunicación de las ONTE} En el núcleo temático sobre Públicos estratégicos presentamos el mapa de públicos de las ONTE y cuáles son los destinarios principales que emergen de las entrevistas. En el conjunto del discurso, este eje temático abarca 103 referencias, que tienen una representación del $13,72 \%$ del total.

Dado que las ONTE tienen conexiones tanto en el país de origen (destino) como en el país de acogida (mercado emisor), la primera observación implícita en las entrevistas es que el mapa de públicos tiene carácter transnacional. Una segunda característica destacable es la distinción entre los destinatarios que son objeto de contacto institucional y los destinatarios de la comunicación de la marca del destino, aunque en la práctica es una separación sutil. La tabla 3 lo resume:

Tabla 3. Públicos estratégicos de las ONTE. Fuente: Elaboración propia.

\begin{tabular}{l|l}
\hline & \multicolumn{1}{c}{ Público } \\
\hline Institucional & $\begin{array}{l}\text { Gobierno, ONT, otras administraciones públicas, socios } \\
\text { institucionales. }\end{array}$ \\
\hline En el destino de origen & Socios de la industria turística y sectores relacionados \\
\hline En el mercado emisor & $\begin{array}{l}\text { Proveedores de servicios de comunicación publicidad, } \\
\text { marketing, etc. }\end{array}$ \\
\hline De la marca & Intermediarios: operadores turísticos y agencias \\
\hline En el mercado emisor & Medios de comunicación \\
\hline & Consumidores (viajeros reales y potenciales) \\
\hline
\end{tabular}

Si atendemos a la importancia que los responsables de las ONTE otorgan a cada uno de estos públicos, observamos en las entrevistas que los principales destinatarios de las acciones de comunicación de las oficinas son, por este orden:

a. Los medios de comunicación del país emisor (en nuestra investigación, España), que actúan como prescriptores ante los turistas potenciales.

b. Los consumidores finales del destino.

c. Los operadores turísticos y las agencias de viaje del país emisor.

\subsection{Herramientas, acciones y medios de promoción}

Este núcleo temático se configura a partir de la información que aportaron las entrevistas sobre las herramientas y acciones de comunicación que aplican las ONTE, y la combinación de acanales de comunicación a través del cual transmiten su mensaje. En el conjunto del discurso, este eje temático tiene una frecuencia de 257 unidades, lo que representa un $34,22 \%$ del total codificado.

Las entrevistas muestran que las ONTE se valen fundamentalmente de acciones de publicity y de relaciones públicas para alcanzar sus objetivos. También se llevan a cabo campañas de publicidad online y, en menor medida, en medios tradicionales. 
Asimismo, se observa que estas herramientas se utilizan de manera complementaria. Los destinatarios, sin embargo, son diferentes: si bien las campañas publicitarias están dirigidas al consumidor final, las acciones de publicity y relaciones públicas están orientadas, principalmente, a profesionales e intermediarios.

En cuanto a la forma de trabajar, las oficinas de turismo suelen apoyarse en agencias de publicidad para la creación de campañas publicitarias, y en gabinetes de prensa o de comunicación para temas de publicity. No obstante, algunas oficinas no externalizan esta última actividad y asumen las funciones de gabinete de prensa.

Como señala una de las personas entrevistadas:

"Trabajamos varios enfoques: uno es trabajar con la prensa y los medios de comunicación en general a nivel redaccional; otro es promoción directa al cliente final a través de campañas clásicas de publicidad o también en la web; y el último enfoque es todo el trabajo con intermediarios, los key accounts: agencias de viajes y tour operadores. $Y$ así funcionamos en todas las oficinas".

Los entrevistados señalan que cada vez se realizan menos acciones de publicidad en medios tradicionales y más acciones en canales online debido, fundamentalmente, a limitaciones presupuestarias. Por otra parte, del contenido de las entrevistas se deduce que las campañas de publicidad que realizan las ONTE en los medios masivos están orientadas a generar conocimiento de marca, en tanto que las campañas en medios online cumplen, fundamentalmente, con el objetivo de llevar tráfico a las páginas webs oficiales de turismo.

La página web oficial del destino es considerado el principal medio de información al público de estas oficinas, ya que en ella el internauta encuentra una serie de contenidos y servicios de interés para organizar su viaje y también para motivar en él el deseo de visitar el destino turístico.

Pero si nos centramos en las acciones de publicity, observamos, en primer lugar, que los planes de marketing y comunicación de las ONTE pueden incluir como objetivos el logro de cantidades específicas de apariciones en la prensa o impactos de audiencia. Para las oficinas, además, la credibilidad por efecto de la firma de un tercero, inherente a la publicity, la coloca por delante de otras acciones de comunicación. Como señala una de las personas entrevistadas:

"Es una de las cosas más importantes, porque lo que sale en una revista tiene mucho más valor si es un artículo que si es un anuncio. Cualquier persona puede decir en un anuncio que [el destino] es bueno y ya está, pero es mucho más difícil conseguir en la prensa escribir sus opiniones y cómo está, porque nunca sabes si un periodista que va [al destino] quizás no le guste, pero si va y le gusta es algo que genera mucha más confianza. Un anuncio es un anuncio, pero conseguir que el medio hable bien de tu producto y tu destino es mucho más difícil y tiene más valor".

Tradicionalmente, la creación de eventos ha sido el principal instrumento de las relaciones públicas para generar publicity. En el caso de las oficinas nacionales de turismo vemos que existe un formato totalmente adaptado a su sector que son los viajes de prensa o press trips y su versión más reciente, los blogs trips, que, al igual que los viajes de familiarización con agentes del sector, buscan la experiencia en primera per- 
sona. A partir de esta experiencia el periodista y el blogger escriben sus reportajes y posts sobre el destino turístico.

En la realización de estos viajes de prensa, las oficinas suelen contar con la colaboración por intercambio de empresas del sector, como líneas aéreas, hoteles u otros proveedores de servicios turísticos.

Por lo que respecta a la organización de estos viajes de prensa, los entrevistados detallan algunas de sus características más relevantes:

a) Selección de periodistas. La cantidad de viajes que se realizan al año es variable, y va desde 20 hasta 100 . Igualmente variable es el número de periodistas de prensa, radio y televisión, así como de fotógrafos, que participan. A la hora de decidir a qué periodista o blogger invitar influyen criterios para qué soporte trabaja, los tema que le interesan, y su reputación como profesional. Normalmente, se organizan grupos de periodistas provenientes de medios y soportes diversos, procurando que no sean competencia entre ellos; pero también hay quien opta por realizar los viajes organizados por soportes.

b) Selección de medios. Los criterios de selección incluyen la calidad, la penetración, el público al que va dirigido, así como la especialización del soporte. Se toman en cuenta publicaciones o programas relacionados a los temas que en el momento está tratando la ONTE, no necesariamente enfocados en el turismo y los viajes. Igualmente, se suele invitar a los periódicos y revistas de las localidades de mayor interés para la oficina dentro del mercado emisor. También se organizan viajes a medida cuando es el medio el que acude a la ONTE con un tema específico que desea tratar. La televisión suele trabajar con este sistema, en lugar de asistir a los press trips.

c) Resultados de los viajes. El resultado esperado de los press y blog trips es la publicación de artículos y reportajes que generen conocimiento sobre el destino y sus atractivos, y que además contribuyan a un estado de opinión favorable. Un viaje puede dar lugar a la publicación de varios trabajos en una revista, espaciados en el tiempo. A veces, pueden tardar hasta un año en publicarse en el caso de los medios impresos.

d) Periodistas frente a bloggers. El fenómeno de los blogs trips es reciente, y aún genera incógnitas. En principio, periodistas y bloggers reciben el mismo tratamiento en cuanto a la selección en base a criterios de calidad. En cuanto al resultado de los viajes, los entrevistados señalan que en los blogs la publicación es inmediata, pero el impacto es reducido, puesto que no tienen la misma penetración que un periódico o revista. Asimismo, entienden que los bloggers suelen ser "más detallistas" y que "buscan más el contraste y la anécdota" que los periodistas en sus textos. En ambos casos, las publicaciones suelen ser favorables y reflejan el mensaje que la ONTE quiere transmitir.

Otras oportunidades para generar publicity pueden provenir de películas o programas de televisión relacionados con el destino, que dan pie a colaboraciones en la promoción aunque la ONTE no haya tenido participación alguna en el desarrollo del producto audiovisual. 
Asimismo, a través de las entrevistas también se identifican acciones que el público percibe como publicity sin serlo. En un punto intermedio entre lo que es la publicidad y la publicity se encuentran los proyectos editoriales monográficos, que, si bien son de pago, el lector no los recibe como publicidad, sino como información ya que son publicaciones de una revista, su contenido es creado por los periodistas y no hace alusión a una marca. Otro tanto puede decirse de la aparición gestionada en espacios de televisión, como por ejemplo "Españoles en el mundo", programa que se transmite a nivel nacional en España y que además puede ser visionado en Internet.

Una vía complementaria para cultivar las relaciones con los medios pasa por mantener una actitud de alerta ante las necesidades informativas de los periodistas, e incluso de sus gustos personales, cuando estos están vinculados de alguna manera con el país de destino. Este tipo de práctica trasciende lo que sería la relación típica periodista-fuente, y va creando una relación entre el comunicador y el destino turístico.

Pero la creación de rapport y el cultivo de una relación directa no están dirigidos únicamente hacia los medios de comunicación, sino también a intermediarios del mercado, como pueden ser las agencias de viajes y los operadores turísticos. Si bien estos últimos han perdido influencia frente al auge de los sitios web de viajes y las líneas aéreas low cost que venden a través de Internet, siguen siendo importantes. Para ellos también suelen programarse visitas, actividades temáticas y encuentros, y se facilitan contactos de negocio con representantes de la industria turística del país a través de workshops o seminarios. Estos formatos también se utilizan para la presentación de las ONTE y sus productos.

Otras líneas de acción son el contacto a través de ferias profesionales (la principal de las cuales en España es FITUR) y los viajes de familiarización o fam trips, en los que los agentes pueden experimentar en primera persona el destino turístico. Así, el principal trabajo de las ONTE con estos públicos consiste precisamente en la colocación del destino en catálogo y en garantizar que las agencias y operadores turísticos cuenten con información de calidad.

En cuanto a acciones de relaciones públicas destinadas al consumidor final, la principal es la participación en ferias de turismo y de temáticas relacionadas al destino. Estos eventos constituyen prácticamente el único punto de contacto directo de la ONTE con el consumidor final, toda vez que estas oficinas no están abiertas al público. También pueden crear acontecimientos específicos, pero resulta menos frecuente.

Finalmente, se percibe que las personas entrevistadas valoran las relaciones públicas de forma muy positiva, como herramientas efectivas para crear vínculos con los medios de comunicación y con colaboradores de la industria, y como alternativa de menor coste a la publicidad.

\subsection{Resultados de las acciones y evaluación}

Este núcleo temático se configura a partir de la información que aportaron las entrevistas sobre el producto de las acciones de publicity y sus sistemas de evaluación; aunque el énfasis está puesto en la obtención de notoriedad en los medios, también se hace referencia a los resultados en general de las acciones para posicionar la marca turística, su impacto directo sobre el destino y los beneficios comparados de las distin- 
tas herramientas que se aplican. En el conjunto del discurso, este eje temático tiene una frecuencia de 81 menciones, con una representación del 10,79\% del total.

$\mathrm{Al}$ analizar sus distintas herramientas de comunicación de forma comparativa, en cuanto a su coste-efectividad, los entrevistados hacen las siguientes observaciones: los buenos resultados pasan por la integración de diferentes herramientas, acciones y canales, y es difícil desligarlos; las relaciones públicas marcan una diferencia porque representan una comunicación directa y humana; la publicity tiene una mejor relación coste-efectividad porque aporta mayor credibilidad que un anuncio publicitario y permite ganar notoriedad con una inversión mínima. Como explica una de las personas entrevistadas:

"Creo que tienen un retorno muchísimo mayor. En el recorte de prensa me doy cuenta, como el recorte me valora el espacio publicitario... una página en un medio cuesta x, pero si un periodista de ese mismo medio me toma una noticia, o me escribe un reportaje, aunque sea de dos páginas y que ha sido algo producto de una inversión mínima como un pasaje aéreo y una estancia, nunca se equipara al costo de una página de publicidad. Entonces yo ya estoy ganando".

Por otro lado, las ONTE coinciden en señalar que es difícil establecer el efecto de acciones concretas sobre el consumidor final, aunque puede tenerse una idea a través de estudios de mercado que se realizan periódicamente a personas que han visitado el destino para saber qué les ha motivado y cómo se han informado, pero estas investigaciones no son sistemáticas y representan una asignatura pendiente para las ONTE.

Para la evaluación específica de las acciones de publicity, los entrevistados diferencian entre lo que son publicaciones en medios impresos y las publicaciones online:

A) Para la evaluación de las acciones de publicity en las publicaciones en medios impresos, las ONTE suelen contratar servicios de clipping externos. El criterio de inclusión de las informaciones varía desde a) incluir solo informaciones que son resultado de las acciones de la ONTE; b) incluir, además de éstas, otros artículos sobre el destino siempre que el tema esté directa o indirectamente relacionado con el turismo; c) considerar todas las informaciones en las que figura la marca del destino. El resumen de prensa incluye, además, la valoración económica de la información como si fuera mancha publicitaria, datos de difusión del medio, cantidad de artículos, etc. El seguimiento se realiza de manera nacional, aunque en algún caso, adicionalmente, también se efectúa desde la oficina central en el país de origen. Por último, el informe de seguimiento y análisis se remite desde la ONTE a la oficina central:

"El servicio de clipping es externo y recoge la información y la valora económicamente, el análisis lo hacemos nosotros. [...] Información turística, exclusivamente. Luego para hacer el informe a nuestra central tenemos en cuenta solo la información generada por nosotros. [...] Localmente lo vemos de forma distinta, evidentemente, la promoción turística es a largo plazo".

B) En las publicaciones online, se constata que no existe entre las ONTE una práctica sistematizada de seguimiento y evaluación. Se aprecian, no obstante, dos ideas compartidas: la medición es sencilla pero, al mismo tiempo, es relativa, pues el pro- 
cedimiento aún no está claramente definido, aunque se reconoce que deberían existir criterios diferenciados respecto de los utilizados para la evaluación de la publicty en medios impresos, más cualitativos.

En general, las ONTE se muestran satisfechas con los resultados obtenidos a través de sus acciones de publicity, tanto a nivel de notoriedad como de tratamiento de la información, pues los artículos suelen reflejar los atributos estratégicos que se quieren promover y son favorables a la marca; entienden que la experiencia del periodista o el blogger en el destino tendría que ser muy mala para escribir algo negativo. Además, se valora de manera muy positiva el impacto de estas publicaciones en la percepción del público y en el conocimiento de las marcas de destinos turísticos. Aunque quizás los resultados solo se aprecian en el largo plazo, las acciones se traducen en la consecución de la imagen deseada y la colocación del destino en el mapa turístico del viajero.

En ese sentido, se observa que los representantes de las oficinas de turismo tienen una percepción positiva sobre la publicity. Entre las valoraciones se destaca que "es una de las herramientas fundamentales" y lo que pierde en "notoriedad" frente a la publicidad, lo gana en "credibilidad" porque "la gente no se fía de la publicidad pura y dura. La gente se fía cuando hay una voz, una imagen, una emoción, una sensación que se transmite y te cuenta una experiencia. Todo eso se da en la publicity".

\subsection{Tendencias y retos}

Este núcleo temático se refiere a las reflexiones de los entrevistados sobre los retos de la promoción de marcas turísticas y la situación de la publicity en el contexto futuro. Incluye también las tendencias en torno al trabajo de las ONTE. En el conjunto del discurso, este eje temático abarca 32 referencias, que tienen una representación del $4,26 \%$ del total.

A través de las entrevistas, identificamos las siguientes tendencias y retos en la práctica de las oficinas de turismo:

a. La promoción turística como vivencia. Como hemos señalado anteriormente, uno de los aspectos por los cuales estas oficinas valoran la publicity es el poder de prescripción de la prensa y bloggers especializados en turismo, viajes y temas vinculantes. Pero dicha prescripción se basa en la "prueba del producto" que se consigue a través de los press y blog trips. La otra influencia importante es la que pueden ejercer los viajeros que han visitado el destino a través de la recomendación y de compartir sus experiencias con sus pares cara a cara y, especialmente el público joven, a través de canales interactivos en Internet. Así, la promoción turística debe estar orientada a la generación de una experiencia placentera en el destino y lograr conseguir prescriptores para la marca.

b. Acciones en medios sociales con visión estratégica. Las ONTE se van adaptando a las necesidades informativas y hábitos de comunicación de los consumidores. Así, desde hace unos pocos años han ido introduciéndose en los llamados medios sociales mediante la creación de blogs y de perfiles en Facebook y Twitter. Se trata, pues, de nuevas formas de prescripción. Las ONTE identifican que la importancia de estos canales va en aumento, y los enfocan principalmente al público joven. Ante el 
auge actual de los medios sociales, parece clara la necesidad de tener una presencia, pero para las oficinas el reto radica en cómo definir estratégicamente esa presencia.

c. Evolución hacia nuevos canales. Se espera que el panorama mediático evolucione cada vez más hacia el mundo online y electrónico, esto implica la adaptación formatos propios del papel, por ejemplo, de los folletos informativos, al entorno digital. Pero también la exploración de nuevos dispositivos para relacionarse con el viajero y proporcionarles servicios con valor añadido, como por ejemplo el desarrollo de aplicaciones móviles que incluyen guías turísticas y localizadores de eventos.

d. El futuro de la publicity. Las relaciones con los medios de comunicación seguirán siendo importantes, aunque se redefina el panorama mediático. Es posible que en el medio o largo plazo algunas publicaciones desaparezcan en formato impreso, pero pervivirán online. Obtener visibilidad en los medios seguirá siendo clave para los destinos turísticos.

\section{Conclusiones}

La aplicación de las técnicas del branding a los destinos turísticos es una actividad en auge que surge en respuesta a un escenario de alta competitividad internacional, donde la diversidad de la oferta ha llevado al desarrollo creciente de la industria turística. Este sector económico que representa el 5\% del PIB mundial (OMT, 2012: 3), se ha visto impactado por el apogeo de los viajes low cost y el acceso cada vez mayor del consumidor, en este caso del consumidor-turista, a información sobre productos y servicios a través de los medios de comunicación off line y online.

Tal como recogen varios estudios citados, los medios de comunicación ejercen una influencia importante en la formación de la imagen de destinos turísticos, y consecuentemente, en la toma de decisiones del viajero. Es por ello que gran parte de los esfuerzos de las organizaciones nacionales de turismo están dirigidos a colocar al destino en una posición positiva ante la opinión pública internacional a través de dichos medios.

En la línea de otros estudios académicos y técnicos, confirmamos en nuestra investigación que la publicity, es decir, el obtener una presencia mediática a través de formatos informativos (no publicitarios) y avalados por la firma de un tercero (periodista o blogger), es una actividad fundamental en la comunicación de los destinos turísticos en el mercado internacional.

Las ONTE se valen de las relaciones públicas para crear una relación con sus públicos intermediarios. En ese sentido, uno de sus principales objetivos es el acercamiento con los medios de comunicación y los periodistas que trabajan en las temáticas relacionadas a turismo y viajes, los cuales son considerados por estas oficinas como prescriptores importantes.

Tradicionalmente, la creación de eventos ha sido el principal instrumento de las relaciones públicas para generar publicity. En el caso de las oficinas de turismo vemos que existe un formato de evento totalmente adaptado a su producto que son los viajes de prensa o press trips y su versión más reciente, los blogs trips.

Los viajes de prensa son una actividad inherente la promoción turística. Constituyen para estas oficinas una manera eficaz de obtener cobertura y transmitir su mensaje a los medios. Estos viajes, así como los tours de familiarización para operadores 
turísticos, intentan recrear la experiencia del turista, para quien todo lo que conforma el producto turístico se concreta en su experiencia de viaje. Los resultados de estas acciones suelen cumplir las expectativas de las ONTE, con la publicación de informaciones que reflejan los atributos del destino y que son favorables a la marca.

Observamos también que existe acuerdo entre las ONTE en cuanto a la importancia de la publicity en sus acciones promocionales, en base a los resultados que obtienen. La publicity es valorada positivamente por su efectividad, su bajo coste frente a otras acciones, como la publicidad, y su capacidad de prescripción frente al público (debido a la credibilidad de los medios de comunicación).

En cuanto al seguimiento y evaluación de la publicity, comprobamos que la práctica se fundamenta en la medición de la cobertura mediática e incluye algunas de las variables de análisis ya tradicionales. Toma en cuenta: el tema, la audiencia y difusión, el tono de la información, la presencia de atributos estratégicos, y la valoración económica de la noticia como si fuera mancha publicitaria (AVE).

Para fines de análisis, por lo general, las ONTE consideran como publicity las noticias que son fruto de sus acciones. Otra posición, incluye también noticias sobre el destino turístico que no son producto de las acciones de la ONTE. Cabe recordar que, de hecho, la mayoría de las publicaciones que sobre un país o destino turístico aparecen en los medios de comunicación surgen en el curso natural de las noticias, no de una planificación estratégica del país, y estas informaciones también tienen un impacto en la imagen del territorio.

Por otro lado, hemos visto que no existe una práctica sistematizada en el seguimiento y análisis de la publicity en medios online. Finalmente, observamos que la práctica de las ONTE transcurre en una adaptación constante a su entorno sociopolítico, económico y tecnológico, y se ve impactada por el desarrollo de nuevos medios basados en Internet. Sin embargo, a pesar de que cada vez más estas oficinas utilizan nuevos canales de comunicación basados en la web social e internet móvil, consideran que de cara al futuro, tener visibilidad en los medios a través de acciones de publicity seguirá siendo importante.

\section{Agradecimientos}

A los directivos y responsables de comunicación de las oficinas de turismo que mostraron su interés en esta investigación y amablemente aceptaron ser entrevistados: Ángeles Alonso-Misol (Oficina de Turismo Bélgica: Flandes y Bruselas), Gilles Dind (Suiza Turismo), Núria López (Oficina de Turismo de Bélgica: Bruselas-Valonia), Paola Dimitri (Oficina de Turismo de República Dominicana para España y Portugal), y Sofie Flensburg (VisitSweden).

\section{Referencias bibliográficas}

ANHOLT, Simon (1998): "Nation-Brands of the Twenty-First Century". Journal of Brand Management, 5 (6), pp. 395-406.

ANHOLT, Simon (2007): Competitive Identity. The New Brand Management for Nations, Cities and Regions. New York, Palgrave MacMillan. 
BLAIN, Carmen, LEVY, Stuart y BRENT RITCHIE, J.R. (2005): "Destination Branding: Insights and Practices from Destination Management Organizations". Journal of Travel Research, 43, pp. 328-338 (DOI: 10.1177/0047287505274646).

CÁCERES, María Dolores (2011): "La construcción social de la realidad: el papel de los profesionales en el establecimiento de la agenda temática". Estudios sobre el Mensaje Periodístico, Vol. 17, núm. 2 (julio-diciembre), pp. 303-324. Madrid, Servicio de Publicaciones de la Universidad Complutense.

CANEL, María José (2007): Comunicación de las instituciones públicas. Madrid, Tecnos.

CASTELLTORT, Magí y MÄDER, Gabriela (2010): "Press media coverage effects on destinations. A Monetary Public Value", en Tourism Management, 31, pp. 724738.

DINNIE, Keith (2008): Nation Branding. Concepts, Issues, Practice. Amsterdam, Butterworth-Heinemann.

DORE, Lynne y CROUCH, Geoffrey I. (2003): "Promoting destinations: An exploratory study of publicity programmes used by national tourism organizations". Journal of Vacation Marketing, 9 (2), pp. 137-151 (DOI: 10.1177/135676670300900203).

GONZÁLEZ, Beatriz (2011): La publicity en la promoción de destinos turísticos.Estudio sobre las prácticas de las Oficinas Nacionales de Turismo Extranjeras (ONTE) en el mercado español. Trabajo de Investigación Doctoral, UAB.

HANUSCH, Folker (2012): "Travel journalists' attitudes toward public relations: Findings from a representative survey". Public Relations Review, 38, pp. 69-75 (DOI: 10.1016/j.pubrev.2011.10.001).

HERNÁNDEZ SAMPIERI, Roberto; FERNÁNDEZ COLLADO, Carlos; y BAPTISTA LUCIO, Pilar (2008): Metodología de la investigación (4ª ed.). México, McGraw-Hill.

KANEVA, Nadia (2011): "Nation Branding: Toward an Agenda for Critical Research". International Journal of Communication, 5, pp. 117-141.

KOTLER, Philip y KELLER, Kevin (2006): Dirección de marketing. (12 edición). Madrid, Pearson Educación.

LODA, Marsha, NORMAN, William y BACKMAN, Kenneth (2007): "Advertising and Publicity: Suggested New Applications for Tourism Marketers", en Journal of Travel Research, 45, pp. 259-265 (DOI: 10.1177/0047287506292688).

LOSADA, Ángel y ESTEVE, Francisco (eds., 2003): El periodismo de fuente. Salamanca, Publicaciones Universidad Pontificia.

OMT (2012): Panorama OMT del turismo internacional, edición 2012. Disponible en http://dtxtq4w60xqpw.cloudfront.net/sites/all/files/pdf/unwto_highlights12_sp_hr. pdf [consulta 5 de mayo de 2013] 
SZONDI, Gyorgy (2008): "Public Diplomacy and Nation Branding: Conceptual Similarities and Differences". Discussion Papers in Diplomacy. Netherlands Institute of International Relations 'Clingendael'. Disponible en: http://www.clingendael.nl/publications/2008/20081022_pap_in_dip_nation_branding.pdf [consulta 3 de mayo de 2013] 